\title{
Relationship between $\beta$-amyloid and structural network topology in decedents without dementia
}

Laura E. Jonkman, PhD, Martijn D. Steenwijk, PhD, Nicky Boesen, MSc, Annemieke J.M. Rozemuller, PhD, Frederik Barkhof, PhD, Jeroen J.G. Geurts, PhD, Linda Douw, PhD, and Wilma D.J. van de Berg, PhD

Neurology ${ }^{\circledR}$ 2020;95:e532-e544. doi:10.1212/WNL.0000000000009910

\author{
Correspondence \\ Dr. Jonkman \\ le.jonkman@ \\ amsterdamumc.nl
}

\section{Abstract \\ Objective}

To investigate the association between $\beta$-amyloid (A $\beta)$ load and postmortem structural network topology in decedents without dementia.

\section{Methods}

Fourteen decedents (mean age at death $72.6 \pm 7.2$ years) without known clinical diagnosis of neurodegenerative disease and meeting pathology criteria only for no or low Alzheimer disease $\mathrm{AD})$ pathologic change were selected from the Normal Aging Brain Collection Amsterdam database. In situ brain MRI included 3D T1-weighted images for anatomical registration and diffusion tensor imaging for probabilistic tractography with subsequent structural network construction. Network topologic measures of centrality (degree), integration (global efficiency), and segregation (clustering and local efficiency) were calculated. Tissue sections from 12 cortical regions were sampled and immunostained for $A \beta$ and hyperphosphorylated tau ( $p$-tau), and histopathologic burden was determined. Linear mixed effect models were used to assess the relationship between $\mathrm{A} \beta$ and $\mathrm{p}$-tau load and network topologic measures.

\section{Results}

$A \beta$ was present in $79 \%$ of cases and predominantly consisted of diffuse plaques; $p$-tau was sparsely present. Linear mixed effect models showed independent negative associations between $A \beta$ load and global efficiency $\left(\beta=-0.83 \times 10^{-3}, p=0.014\right)$, degree $(\beta=-0.47, p=0.034)$, and clustering $\left(\beta=-0.55 \times 10^{-2}, p=0.043\right)$. A positive association was present between $\mathrm{A} \beta$ load and local efficiency $\left(\beta=3.16 \times 10^{-3}, p=0.035\right)$. Regionally, these results were significant in the posterior cingulate cortex (PCC) for degree $(\beta=-2.22, p<0.001)$ and local efficiency $\left(\beta=1.01 \times 10^{-2}, p=\right.$ $0.014)$ and precuneus for clustering $\left(\beta=-0.91 \times 10^{-2}, p=0.017\right)$. There was no relationship between $\mathrm{p}$-tau and network topology.

\section{Conclusion}

This study in deceased adults with $\mathrm{AD}$-related pathologic change provides evidence for a relationship among early $A \beta$ accumulation, predominantly of the diffuse type, and structural network topology, specifically of the PCC and precuneus.

\footnotetext{
From the Departments of Anatomy and Neurosciences (L.E.J., M.D.S., N.B., J.J.G.G., L.D., W.D.J.v.d.B.), Pathology (A.J.M.R.), and Radiology and Nuclear Medicine (F.B.), Amsterdam UMC, Vrije Universiteit Amsterdam, the Netherlands; and Institutes of Neurology and Healthcare Engineering (F.B.), University College London, UK.

Go to Neurology.org/N for full disclosures. Funding information and disclosures deemed relevant by the authors, if any, are provided at the end of the article. 


\section{Glossary}

$\mathbf{A} \beta 42=\beta$-amyloid 42; $\mathbf{A D}=$ Alzheimer disease $\mathbf{C I}=$ confidence interval $\mathbf{D A B}=$ diaminobenzidine tetrahydrochloride dehydrate; DTI = diffusion tensor imaging; FDR = false discovery rate; FLAIR = fluid-attenuated inversion recovery; $\mathbf{G M}=$ gray matter; NABCA = Normal Aging Brain Collection Amsterdam; NFT = neurofibrillary tangle; NIA-AA = National Institute of Aging-Alzheimer's Association; $\mathbf{p}$-tau = hyperphosphorylated tau; TBS = Tris-buffered saline; TE $=$ echo time; TI = inversion time; $\mathbf{T R}=$ repetition time; $\mathbf{W M}=$ white matter.

With increasing age, cognitively healthy people may show substantial $\beta$-amyloid $(\mathrm{A} \beta$ ) and hyperphosphorylated tau ( $\mathrm{p}$ tau) protein accumulation and deposits. ${ }^{1}$ This process can be seen as pathologic change in normal aging, or in the evolution of Alzheimer disease $(\mathrm{AD})^{2,3}$ As such, the cascade of biological processes underlying $\mathrm{AD}$ can occur decades before the onset of $\mathrm{AD}$-related symptoms. ${ }^{1,4}$ Capturing age and $\mathrm{AD}$ related pathologic change prior to onset of noticeable symptoms can be promising for early identification of individuals at risk for developing $\mathrm{AD} .^{5}$

The characteristic spatial pattern of $A \beta$ distribution as described by Braak and $B{ }^{2} k^{6}$ suggests that $A \beta$ spreads from regions exhibiting $A \beta$ to interconnected neuronal regions though large-scale cellular networks. ${ }^{7}$ Advances in MRI analysis and graph theory have made it possible to study this brain network organization, ${ }^{8}$ which have been extensively applied in studies on aging and $\mathrm{AD}$-related cognitive decline. ${ }^{9,10}$ Research on the association between early $A \beta$ accumulation and brain network topology have used proxies for $A \beta$ accumulation, such as $\mathrm{CSF}^{11}$ or $\mathrm{A} \beta$ PET. ${ }^{12}$ However, $\mathrm{CSF}$ is a nonregional specific marker of pathologic state, and A $\beta$ PET primarily binds to fibrillar dense-core $A \beta$ aggregates rather than non-neuritic diffuse plaques, which are generally seen in early stages of $A \beta$ accumulation. ${ }^{13,14}$

Our aim was to investigate the radiologic-pathologic association between pathologically defined early-stage $A \beta$ and p-tau load and structural network topologic measures of centrality, integration, and segregation in non-neurologic brain donors, using a unique within-subject postmortem MRI and histopathology approach.

\section{Methods}

\section{Standard protocol approvals, registrations, and patient consents}

Prior to death, all donors were registered with the body bequest program at the Department of Anatomy and Neurosciences, Amsterdam UMC-location VUmc, Amsterdam, the Netherlands. All donors gave written informed consent for the use of their tissue and medical records for research purposes. MRI, autopsy, radiologic (F.B.), and neuropathologic (A.J.M.R.) assessment were done through the Normal Aging Brain Collection Amsterdam (NABCA) pipeline (nabca.eu). ${ }^{15}$ Permission for performing MRI, autopsies, and use of tissue was granted by the institutional ethics review board.

\section{Donor inclusion}

From the NABCA biobank, donors were selected based on the following inclusion and exclusion criteria. (1) No clinical diagnosis of neurodegenerative disease in their medical history. (2) Availability of in situ MRI without signs of overt neurodegenerative or major vascular disease. (3) Availability of a neuropathologic diagnosis, ${ }^{15}$ and if present, with pathology meeting criteria for no or low $\mathrm{AD}$ pathologic change according to the National Institute of Aging-Alzheimer's Association (NIA-AA) guidelines, ${ }^{16,17}$ and without other neurologic disease.

\section{Data availability}

Data are available upon reasonable request through NABCA (nabca.eu). ${ }^{15}$

\section{In situ MRI acquisition and volume measurements}

In situ (brain still in cranium) imaging data were collected with a 3T whole-body MRI system (Signa, MR750; GE Medical Systems, Milwaukee, WI) using an 8-channel head coil. Structural imaging involved the use of a sagittal 3D T1weighted fast spoiled gradient-echo sequence (repetition time [TR], 7 ms; echo time [TE], 3 ms; inversion time [TI], 450 $\mathrm{ms} ; 15^{\circ}$ flip angle; slice thickness $1.0 \mathrm{~mm}$; in-plane resolution $1.0 \times 1.0 \mathrm{~mm}^{2}$ ) for cortical gray matter (GM) segmentation, and a 3D fluid-attenuated inversion recovery image (FLAIR; TR, 8,000 ms; TE, $130 \mathrm{~ms}$; TI, 2,000-2,250 ms [optimized per case to account for temperature differences leading to variable CSF suppression], sagittal slice thickness $1.2 \mathrm{~mm}$; inplane resolution $1.11 \times 1.11 \mathrm{~mm}^{2}$ ) for detection of white matter (WM) abnormalities. In addition, 2D echoplanar diffusion tensor imaging (DTI) was performed (TR, 7,400 ms; TE, $92 \mathrm{~ms}$; slice thickness $2 \mathrm{~mm}$; in-plane resolution $2.0 \times$ $2.0 \mathrm{~mm}^{2}$ ), using a twice refocused SE diffusion technique with 30 noncollinear gradient-encoding directions with $\mathrm{b}$ values $=$ 700 seconds $/ \mathrm{mm}^{2}$ and 5 nonweighted volumes. From 3D T1 images, normalized whole brain, WM, and GM volume was estimated using SIENAX (part of FSL 5.0.9; fsl.fmrib.ox.ac. $\mathrm{uk} /)^{18}$ and normalized hippocampal volume using FIRST (part of FSL) after lesion filling.

\section{Construction of structural connectomes}

WM abnormalities were segmented on FLAIR images using multiview convolutional neural network with batch normalization followed by manual editing, yielding lesion maps, which were registered to the $3 \mathrm{D}$ T1 images. Lesion refilling was performed using LEAP $^{19}$ to minimize the impact of lesions on subsequent automated segmentations. The 
transformation between 3DT1 and diffusion-weighted images was derived by using boundary-based registration. ${ }^{20}$ The diffusion-weighted images were corrected for motion and eddy current distortion using FMRIB's Diffusion Toolbox (FSL-FDT; part of FSL 5.0.9). A surface based version of the automated anatomical labeling atlas was used to parcellate the cortex into 78 areas $^{21}$ and FIRST (part of FSL) was used to delineate deep GM, constituting a total 92 nodes. Subsequently, bedpostx was run to build up diffusion parameter distributions at each voxel, after which probabilistic tractography was conducted (probtrackx2, part of FSL, 5,000 streamlines per voxel) to obtain probabilistic maps of WM connections running between all pairs of nodes, resulting in a nonweighted $92 \times 92$ structural network for each participant. The tractography was corrected for seed volume, target volume, and (multiplied by) length of tracts. ${ }^{22}$

\section{Computation of graph theory measures}

The resulting connectivity matrixes were analyzed in MATLAB (MATLAB R2012a, The MathWorks Inc., Natick, MA, 2000). The matrix was symmetrized by computing the average between the original matrix and its transpose. The edges were thresholded (range 5\%-45\%, increments of 5\%) to reduce the number of false-positive connections; the top $20 \%$ strongest links were retained, which approximates the most optimal balance in cost vs efficiency of the brain. ${ }^{23}$ Subsequently the edges were binarized. Similarity between the topographic location of the edges between cases was determined using the Dice ${ }^{24}$ similarity coefficient. The average $( \pm S D)$ Dice similarity coefficient was $0.82( \pm 0.02)$, indicating good correspondence between participants in terms of the location of connections. From the binarized matrix, graph theoretical characteristics were computed using the Brain Connectivity Toolbox as described previously. ${ }^{25}$ In the current study, we included network degree as a measure of centrality, ${ }^{25}$ global efficiency as a measure of integration, and local efficiency as a measure of segregation ${ }^{26}$ (figure 1).

Network degree of a brain region (node) is defined by the number of connections (edges) that link the region to other brain regions (nodes). A high degree means that a region is highly connected to other regions. ${ }^{25}$
Global efficiency is the average inverse number of edges that need to be traveled to go from one node to the other in the network (inverse of the average path length).

Local efficiency is defined as the inverse of the shortest path length (number of steps, or links, between network nodes) between connected nodes that are neighbors with the node of interest.

Clustering is defined as the fraction of triangles around a node and represents the degree to which neighbors of a node tend to also be connected.

To indicate regions as "hubs" (the regions with the top $10 \%$ highest connections), for each region within a participant network degree and betweenness centrality (the fraction of all shortest paths in the network that contain a given node $)^{25}$ were calculated. Subsequently, median network degree and median betweenness centrality were calculated for a region across all participants. Finally, these 2 measures were independently inverse ranked and summed. The highest rank scores indicated hub regions.

\section{Tissue sampling of cortical regions}

After in situ MRI, the donor was transported to the mortuary for subsequent rapid autopsy of the brain. From the right hemisphere, tissue blocks were dissected according to a strict anatomical protocol ${ }^{15}$ to ensure consensus in regions across participants. For the current study, tissue blocks from 12 standardized cortical brain regions were collected: the precuneus, posterior cingulum, frontal pole, middle frontal cortex, inferior parietal cortex, temporal pole, superior frontal cortex, insula cortex, anterior cingulate cortex, middle temporal cortex, and occipital cortex. In addition, the middle hippocampus with the entorhinal cortex was dissected.

\section{Immunostaining for $A \beta$ and $p$-tau}

Serial sections of paraffin-embedded tissue blocks were cut at $20 \mu \mathrm{m}$ (Leica [Newcastle, UK] Microtome) and mounted onto glass slides. A Nissl staining (for anatomical orientation) and $A \beta$ immunohistochemistry was performed on all 12 cortical regions. For measuring p-tau pathology, sections
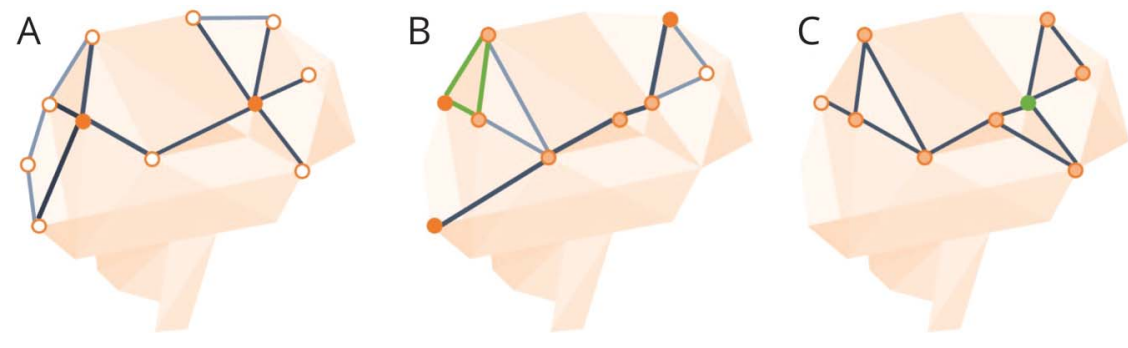

(A) Degree: higher degree regions (e.g., filled in orange) have more connections. ${ }^{25}$ (B) Global efficiency provides a measure for how easily information can be transmitted from one side of the network to the other (dark line), taking the inverse of the average path length between nodes. Local efficiency (top left in green) is defined as the inverse of the shortest path length between connected nodes that are neighbors with the node of interest. The shortest path is defined as number of steps, or links, between network nodes. ${ }^{26}$ (C) Clustering coefficient is defined as the fraction of triangles around a node (green node) and represents the degree to which neighbors of a node tend to also be connected. ${ }^{25}$ 
were cut at $6 \mu \mathrm{m}$ of 8 cortical regions (precuneus, anterior and posterior cingulate, superior and middle frontal cortex, inferior parietal cortex, middle temporal cortex, and entorhinal cortex).

Sections were deparaffinized and rehydrated in a graded series of xylene and ethanol before following a standard Nissl protocol. The sections for the $A \beta$ immunostaining were deparaffinized and rehydrated, after which they were washed in Tris-buffered saline (TBS) followed by antigen retrieval in citrate buffer ( $\mathrm{pH}$ 6.0) at a temperature of $95^{\circ}$ for 30 minutes. After cooling down for approximately 45 minutes, they were again washed in TBS followed by an $80 \%$ formic acid block for 5 minutes. The sections were subsequently rinsed for 10 minutes in running demi water and a 5-minute wash in TBS. This was followed by preventing background noise by bleaching for the endogenous peroxidase for 20 minutes $(0.3 \%$ $\mathrm{H}_{2} \mathrm{O}_{2}$ in $50 \%$ ethanol) and another $3 \times 5$ minutes wash with TBS. Finally, the sections were incubated with a primary mouse anti-A $\beta$ antibody (6F/3D, 1:1,000; Dako, Glostrup, Denmark) in a blocking solution ( $2 \%$ bovine serum albumin in TBS-Tx) for approximately 24 hours at $4^{\circ}$.

The second day commenced with a $3 \times 5$ minutes wash in TBS, followed by a 1-hour incubation at room temperature with Envision (horseradish peroxidase mouse). This was followed by a $2 \times 5$ minutes TBS wash and a 5-minute Tris- $\mathrm{HCl}$ wash, after which the peroxidase reaction was developed with 3,3'-diaminobenzidine tetrahydrochloride dehydrate (DAB; Dako) as a chromogen. The sections were subsequently washed in Tris- $\mathrm{HCl}$ and running demi water, followed by a hematoxylin counterstain for 1 minute, which was developed by running tap water for 5 minutes. Finally, the sections were dehydrated and cleared in a graded series of ethanol and xylene, and closed with entellan and a coverslip.

The 6- $\mu \mathrm{m}$ sections were automatically immunostained with Ventana Benchmark Ultra (Roche Diagnostics, Mannheim, Germany) using standard CC1 pretreatment and incubation with prediluted primary antibodies against p-tau (AT8; 1: 10.000, Innogenetics, Alpharetta, GA).

\section{Semiquantitative and quantitative scoring of $A \beta$}

A semiquantitative analysis of $A \beta$ was manually performed on a light microscope (Leica). Each section was placed under the microscope at 200x magnification for an in-depth assessment of the types of plaques present across the section, including diffuse, classic, subpial, and perivascular $A \beta$ depositions. ${ }^{27}$ These were scored on a 4-point scale $(0=$ none; $1=$ sparse $[1$ or 2 depositions]; $2=$ [more than 2 depositions or in multiple places]; 3 = frequent [multiple larger depositions in different areas, covering (almost) all of the cortical area]).

The quantitative analysis was performed using a brightfield microscope (Leica, DM5000B; Leica Microsystems, Wetzlar,
Germany) with a Nuance camera (Nuance 3.02; Perkin Elmer Inc., Hopkinton, MA). With a $100 \times$ magnification, cortical areas that contained all 6 layers within the field of view were photographed in a systematic manner as "cubes." Each section contained a minimum of 3 and maximum of 10 cubes. Parts of WM and blood vessels within a cube were manually excluded. The load of $A \beta$ pathology was subsequently quantified as the percentage area of $A \beta$ deposits within the image cubes with the multispectral imaging system. The specific spectra of $D A B$ and hematoxylin were used to unmix the image cubes, and the Nuance software colocalization tool was used to calculate the percentage $A \beta$ deposits in each cube (figure 2). For each cortical region, an average percentage $A \beta$ was calculated across cubes. The final dataset consisted of 145 analyzed tissue sections.

\section{Semiquantitative scoring of $\mathbf{p}$-tau}

For the analysis of p-tau load, percentage area would not be a suitable method in this cohort, as AT8 immunoreactivity is sparse and values would be small. Therefore we adapted a semiquantitative method, which was performed manually on a light microscope (Leica). Each section was placed under the microscope at 100x and 200x magnification for an in-depth assessment of presence of p-tau immunoreactivity. Presence of p-tau included any AT8 immunoreactivity such as threads (pre-)tangles, dystrophic neurites, or thorny or fuzzy astrocytes in all layers of the cortex. This was subsequently scored on a 4-point scale, adapted from a scoring method by Alafuzoff and et al. ${ }^{28}$ Scoring consisted of $0=$ absent AT8 immunoreactivity; $1=$ very sparse AT8 immunoreactivity $(<\sim 5$ observations throughout the section, only visible with $200 \times$ magnification), which is less than the "low +" scoring by Alafuzoff et al. ${ }^{28} ; 2=$ sparse AT8 immunoreactivity (barely noted at 100x magnification), similar to the "low +" scoring by Alafuzoff et al. ${ }^{28} ; 3=$ moderate AT8 immunoreactivity (easily seen at both magnifications); and $4=$ high AT8 immunoreactivity (seen even without the microscope), similar to the "moderate ++ " and "high +++" scoring method of Alafuzoff et al. ${ }^{28}$

\section{Statistical analysis}

Descriptive and statistical analysis was performed using IBM SPSS 22.0 for Windows (SPSS, Inc., Chicago, IL). With a bivariate correlation, the relationship between $A \beta$ load and age was assessed, with a Kruskal-Wallis test assessing the relationship between $A \beta$ load and genotype. To account for multiple (i.e., 12) brain regions within cases (i.e., non-independent, nested data), the relationship between network measures and percent $A \beta$ load or $p$-tau was assessed with (multiple) linear mixed models. The graph theoretical measures were the dependent variables, percent $A \beta$ load or $p$-tau the main effect factors, with age, sex, and postmortem delay as covariates. The intercept was included as random effect. $p$ Values $<0.05$ were considered significant. For the independent regional analyses (i.e., the 12 regions with tissue sections), the Benjamini and Hochberg false discovery rate (FDR) correction for multiple comparisons was applied. ${ }^{29}$ 


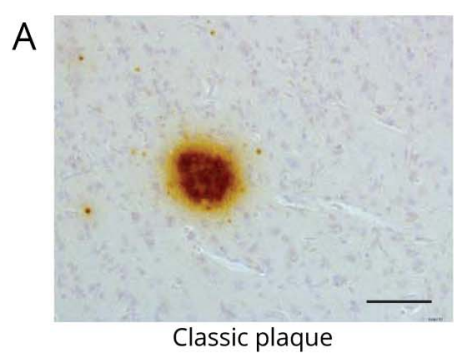

B

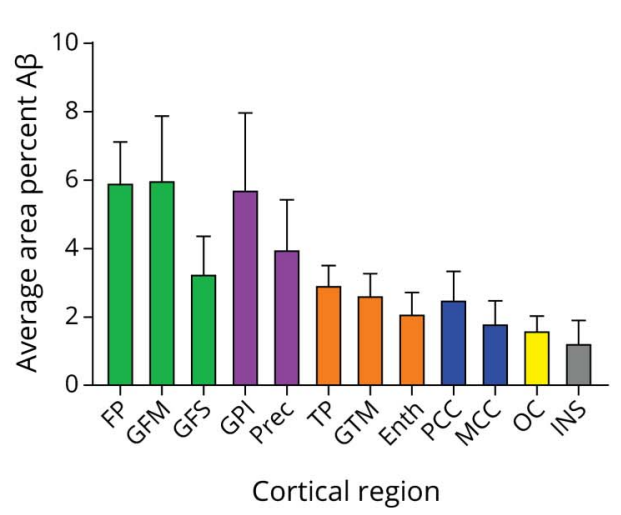

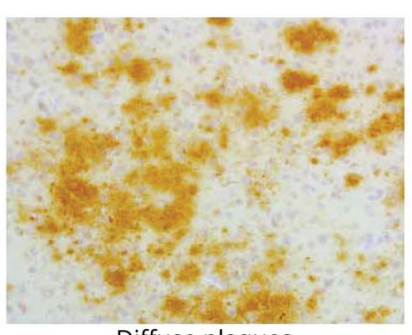

Diffuse plaques

C

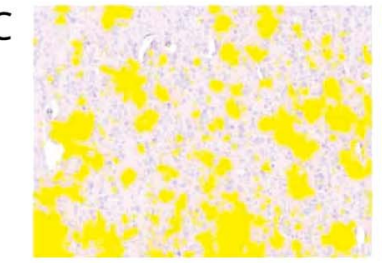

Case $10, \mathrm{GPI}, 27 \%$ area $A \beta$

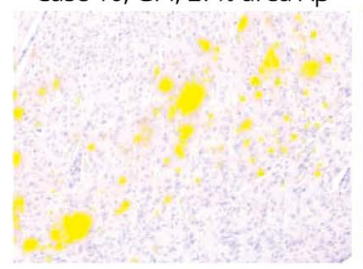

Case 10, PCC, $5 \%$ area A $\beta$

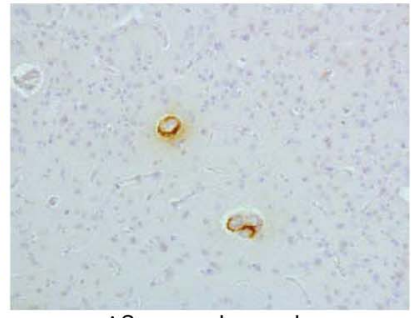

$A \beta$ around vessels

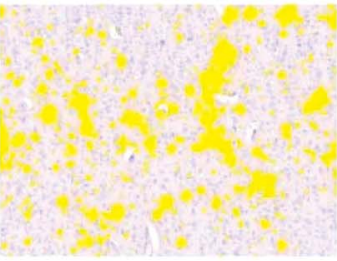

Case $10, \mathrm{GPI}, 17 \%$ area $\mathrm{A} \beta$

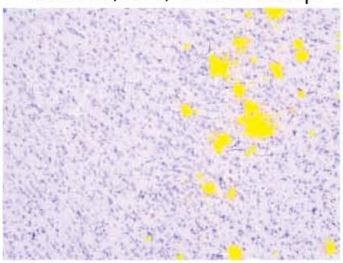

Case $01, \mathrm{FP}, 2.6 \%$ area $A \beta$

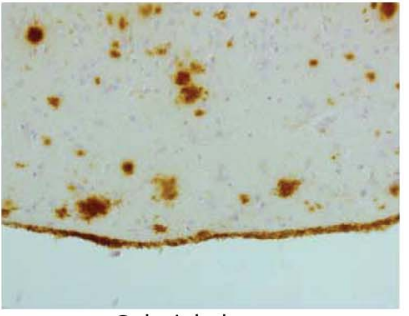

Subpial plaque

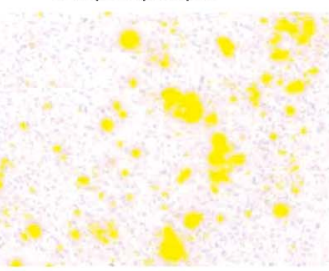

Case 10, Prec, $11 \%$ area $A \beta$

Case $01, \mathrm{GFM}, 1 \%$ area $A \beta$

(A) Morphology of A $\beta$ depositions. From left to right: classic plaque, diffuse plaques, $A \beta$ around vessels, and subpial plaque depositions. Scale bar = $100 \mu$ m. (B) Distribution of $A \beta$ pathology (mean and SEM). Across cortical regions in all cases, there was more average area percent $A \beta$ accumulation in the frontal cortex (in green) and parietal cortex (in purple) than in the temporal cortex (in orange), cingulate cortex (in blue), occipital cortex (OC; in yellow), and insular cortex (INS; in gray). (C) Indications of area percentage A $\beta$ (in yellow) in cubes as measured with the Nuance spectral imager. Scale bar $=200 \mu$ m. Enth = entorhinal cortex; FP = frontal pole; GFM = middle frontal gyrus; GFS = superior frontal gyrus; GPI = inferior parietal gyrus; GTM = middle temporal gyrus; $M C C=$ middle cingulate cortex; PCC = posterior cingulate cortex; Prec = precuneus; TP = temporal pole.

\section{Results}

\section{Donor characteristics}

Brain sections from 14 donors (8 female/6 male) with an average age of 73 years (range 59-87) were included in the study. Mean $( \pm \mathrm{SD})$ postmortem delay was 9 hours 18 minutes ( \pm 3 hours). Most participants had atrophy scores as expected for their age (for example, medial temporal atrophy scores $>2$ for adults over 75 years of age).$^{30}$ Eleven decedents showed $A \beta$ pathology, but this did not exceed Thal phase 3 (e.g., depositions in striatum or thalamus, but not brainstem regions). ${ }^{31}$ Eleven decedents showed p-tau pathology, but this did not exceed Braak neurofibrillary tangle (NFT) stage 2 (NFTs not beyond the entorhinal cortex). ${ }^{6}$ Table 1 provides demographic, neuropathologic, and radiologic details of the donors. There was no relationship between percent $A \beta$ load and age, or $A \beta$ load and $A P O E$ genotype.

\section{$A \beta$ and $p$-tau morphology and load}

Ten decedents showed $A \beta$ depositions in the selected cortical regions. When $A \beta$ depositions were present, they predominantly consisted of diffuse plaques (median 2; range 1-3). A few subpial depositions, classic plaques, and perivascular $A \beta$ depositions were also observed (all median 0; range 0-3 for subpial and perivascular $A \beta$ depositions and range $0-2$ for classic plaque depositions). Regarding variation of plaque types, 96 (of 145 included) tissue sections showed some $A \beta$ pathology; 32 tissue sections had only 1 type of plaque present (diffuse plaques), 19 tissue sections had 2 types of plaques (13 diffuse and subpial, 3 diffuse and classical, 3 diffuse and perivascular depositions), 37 sections had 3 types of plaques ( 28 diffuse, subpial, and classic, 7 diffuse, subpial, and perivascular depositions, and 2 diffuse, classic, and perivascular depositions), and 8 sections had all 4 types of plaques present across 6 different regions (anterior cingulate, middle frontal cortex, temporal pole, entorhinal cortex, inferior parietal lobe, and occipital lobe).

In cases with amyloid depositions, distribution of $A \beta$ pathology average area percent $A \beta$ load $( \pm S E M)$ was more abundant in frontal $(5.09 \pm 1.35)$ and parietal $(4.87 \pm 1.82)$ regions than in the temporal $(2.58 \pm 0.58)$, cingulate $(2.19 \pm 0.79)$, occipital $(1.63 \pm 0.39)$, and insula $(1.26 \pm 0.65)$ regions (see figure 2$)$.

Twelve cases showed sparse p-tau positivity. Cortical regions that contained AT8 immunoreactivity were the entorhinal cortex, middle temporal cortex, superior and middle frontal cortex, precuneus, inferior parietal cortex, and anterior and posterior cingulate cortex. Fifty-seven (of 95 included) tissue sections showed some AT8 immunoreactivity: 50 sections 


\begin{tabular}{|c|c|c|c|c|c|c|c|c|c|c|c|c|c|c|c|c|}
\hline \multicolumn{5}{|c|}{ Clinical characteristics } & \multicolumn{5}{|c|}{ Pathologic and genetic characteristics $^{a}$} & \multicolumn{7}{|c|}{ Radiologic characteristics $^{\mathbf{b}}$} \\
\hline Case & Sex & Age, y & $\begin{array}{l}\text { PMD, } \\
\mathrm{h}: \mathrm{m}\end{array}$ & Cause of death & $\begin{array}{l}\text { Pathologic } \\
\text { classification }\end{array}$ & $\begin{array}{l}\text { AD } \\
\text { status }\end{array}$ & $\begin{array}{l}\text { Thal } \\
\text { phase }\end{array}$ & $\begin{array}{l}\text { Braak } \\
\text { NFT }\end{array}$ & APOE & GCA & $\begin{array}{l}\text { MTA, } \\
\text { R/L }\end{array}$ & NBV & NGMV & NWMV & $\begin{array}{l}\text { Hippocampal } \\
\text { volume, }{ }^{c} \mathrm{R}\end{array}$ & $\begin{array}{l}\text { Hippocampal } \\
\text { volume, }{ }^{c} L\end{array}$ \\
\hline 1 & M & 68 & $8: 40$ & $\begin{array}{l}\text { Euthanasia } \\
\text { (prostate carcinoma) }\end{array}$ & A1 B1 C0 & Low & 2 & 1 & E3/E4 & 0 & $0 / 0$ & 1.61 & 0.85 & 0.76 & 5.31 & 5.06 \\
\hline 2 & $\mathrm{~F}$ & 71 & $6: 50$ & Lung carcinoma & A1 B1 C0 & Low & 2 & 1 & E3/E4 & 1 & $0 / 1$ & 1.48 & 0.77 & 0.71 & 4.85 & 5.21 \\
\hline 3 & $\mathrm{~F}$ & 87 & 8:35 & Urinary tract infection & $\mathrm{AO} B 1 \mathrm{CO}$ & No & 0 & 1 & E3/E3 & 1 & $1 / 1$ & 1.39 & 0.73 & 0.66 & 5.00 & 3.93 \\
\hline 4 & $\mathrm{~F}$ & 72 & $7: 20$ & Heart failure & AO BO CO & No & 0 & 0 & E3/E3 & 0 & $0 / 0$ & 1.52 & 0.80 & 0.72 & 6.52 & 6.35 \\
\hline 5 & $\mathrm{~F}$ & 69 & 13:00 & $\begin{array}{l}\text { Pulmonary } \\
\text { embolism }\end{array}$ & A1 B1 C0 & Low & 1 & 1 & E3/E3 & 1 & $0 / 1$ & 1.38 & 0.70 & 0.67 & 5.35 & 4.68 \\
\hline 6 & M & 59 & $8: 00$ & $\begin{array}{l}\text { Euthanasia } \\
\text { (adrenal cancer) }\end{array}$ & A1 B1 C0 & Low & 2 & 1 & E3/E4 & 0 & $0 / 0$ & 1.49 & 0.76 & 0.73 & 5.25 & 4.65 \\
\hline 7 & M & 74 & $16: 00$ & Colorectal cancer & A1 B1 C0 & Low & 2 & 1 & NA & 0 & $2 / 2$ & 1.47 & 0.78 & 0.69 & 4.28 & 3.81 \\
\hline 8 & M & 72 & 11:45 & Esophagus cancer & A2 B1 C0 & Low & 3 & 1 & E2/E3 & 1 & $1 / 1$ & 1.45 & 0.72 & 0.74 & 4.03 & 4.46 \\
\hline 9 & M & 77 & 11:40 & Pneumonia & A1 B1 C0 & Low & 1 & 1 & E2/E3 & 1 & $1 / 1$ & 1.46 & 0.72 & 0.75 & 4.39 & 4.22 \\
\hline 10 & $\mathrm{~F}$ & 79 & $5: 25$ & Unknown & A2 B1 C1 & Low & 3 & 2 & E3/E3 & 0 & $0 / 0$ & 1.52 & 0.79 & 0.73 & 4.77 & 4.97 \\
\hline 11 & $\mathrm{~F}$ & 78 & 10:00 & Unknown & A1 B1 C0 & Low & 1 & 1 & E3/E3 & 0 & $1 / 2$ & 1.52 & 0.78 & 0.74 & 4.27 & 3.57 \\
\hline 12 & $\mathrm{~F}$ & 77 & 4:30 & Cecum tumor & A1 B1 Co & Low & 2 & 2 & E3/E3 & 1 & $1 / 2$ & 1.50 & 0.71 & 0.78 & 5.20 & 4.24 \\
\hline 13 & $\mathrm{~F}$ & 59 & $8: 10$ & Euthanasia (COPD) & AO BO CO & No & 0 & 0 & E3/E3 & 1 & $0 / 0$ & 1.46 & 0.78 & 0.68 & 5.60 & 5.67 \\
\hline 14 & M & 74 & 10:20 & $\begin{array}{l}\text { Euthanasia } \\
\text { (unknown) }\end{array}$ & A2 B1 C0 & Low & 3 & 2 & E3/E3 & 2 & $1 / 2$ & 1.43 & 0.72 & 0.70 & 4.29 & 4.09 \\
\hline Mean \pm SD & & $72.6 \pm 7.2$ & \multicolumn{9}{|l|}{$9: 18 \pm 2: 58$} & $1.48 \pm 0.06$ & $0.76 \pm 0.04$ & $0.72 \pm 0.03$ & $4.94 \pm 0.65$ & $4.64 \pm 0.74$ \\
\hline \multicolumn{17}{|c|}{ 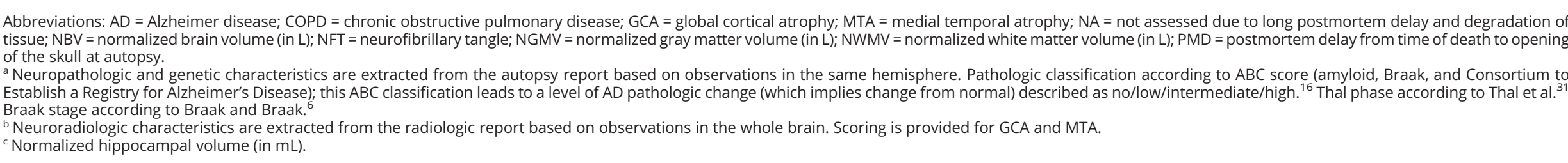 } \\
\hline
\end{tabular}


"very sparse" reactivity, 5 sections "sparse” reactivity (case 10 anterior and posterior cingulate cortex and temporal cortex; cases 11 and 12 entorhinal cortex), and 2 sections "moderate" reactivity (case 10 and 14 entorhinal cortex).

\section{Relationship between $A \beta$ load and global and regional volume}

When assessing the association between average percent $A \beta$ load across all included regions and independent measures of normalized global brain volume, normalized GM volume, and normalized WM volume, there was no association between $A \beta$ load and these volume measures. In addition, there was no association between $A \beta$ load and volume of the left and right hippocampus.

\section{Tractography: identification of hub regions}

The 10\% highest ranked degree and betweenness centrality regions, also referred to as hubs, were the (left and right) putamen, (left and right) thalamus, (left and right) posterior cingulate cortex, (right and left) pallidum, and right olfactory cortex, respectively. When only considering cortical regions, the (left and right) posterior cingulate cortex, (left and right) precuneus, (left and right) olfactory cortex, right insular cortex, and right superior parietal cortex were hub regions, which overlap to what has been found in the in vivo literature. ${ }^{32,33}$

For our analysis, 12 right hemispheric cortical regions were selected, and presence of both high and low hub regions were confirmed; the posterior cingulate, insula, and precuneus had the highest hubness and the middle frontal cortex and inferior parietal cortex the lowest hubness (figure 3).

\section{Relationship between $A \beta$ load and network topology}

On a global, whole brain level ( $\mathrm{n}=14$ cases), an association between average percent $A \beta$ load and global efficiency was found $\left(\beta=-0.83 \times 10^{-3}[95 \%\right.$ confidence interval $(\mathrm{CI})-1.4 \times$ $\left.10^{-3},-0.2 \times 10^{-3}\right] ; p=0.014$ ) (figure $4 \mathrm{~A}$ ), indicating that higher $A \beta$ load is related to lower global efficiency. This result remained significant at thresholds $15 \%-25 \%$ (table 2). On a local level ( $n=145$ sections across 12 regions), a significant association between percent $A \beta$ load and degree $(\beta=-0.47$ $[95 \% \mathrm{CI}-0.91,-0.03] ; p=0.034)$, clustering $(\beta=-0.55 \times$ $\left.10^{-2}\left[95 \% \mathrm{CI}-0.1,-0.1 \times 10^{-2}\right] ; p=0.043\right)$, and local efficiency $\left(\beta=3.16 \times 10^{-3}\left[95 \%\right.\right.$ CI $\left.0.2 \times 10^{-3}, 6.1 \times 10^{-3}\right] ; p=$ $0.035)$ was found. This indicates that higher $A \beta$ load is related to lower degree and higher local efficiency. These results did

Figure 3 Average structural connectivity matrix and distribution of hubness across cortical regions of the right hemisphere

A

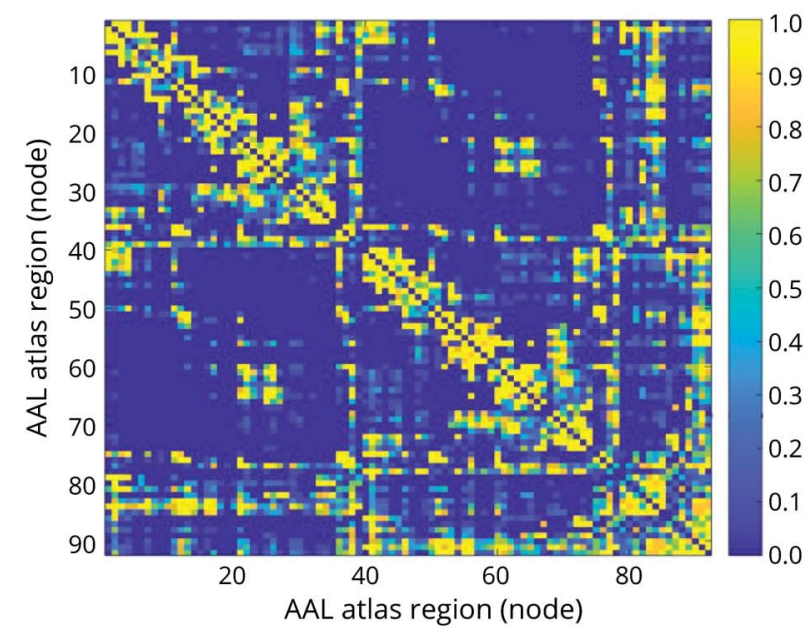

B

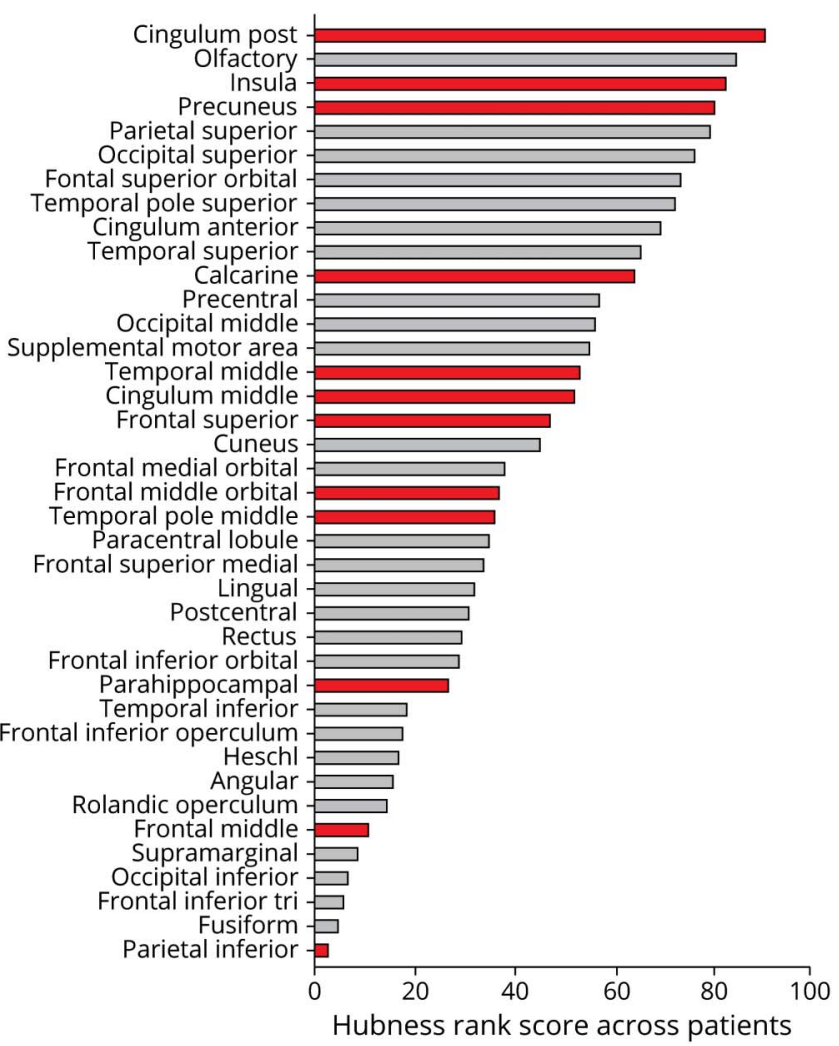

(A) The structural connectivity matrix was computed on a whole-brain (92 nodes) level. Shown here is the average binary matrix across 14 subjects. (B) Hub rank (based on network degree and betweenness centrality) of the right hemisphere across 14 subjects, partitioned according to the automated anatomical labeling (AAL) atlas. Highest summed rank regions (top) to lowest summed rank regions (bottom). Highlighted in red are the tissue regions included in our model assessing association between $\beta$-amyloid load and structural network topology. 

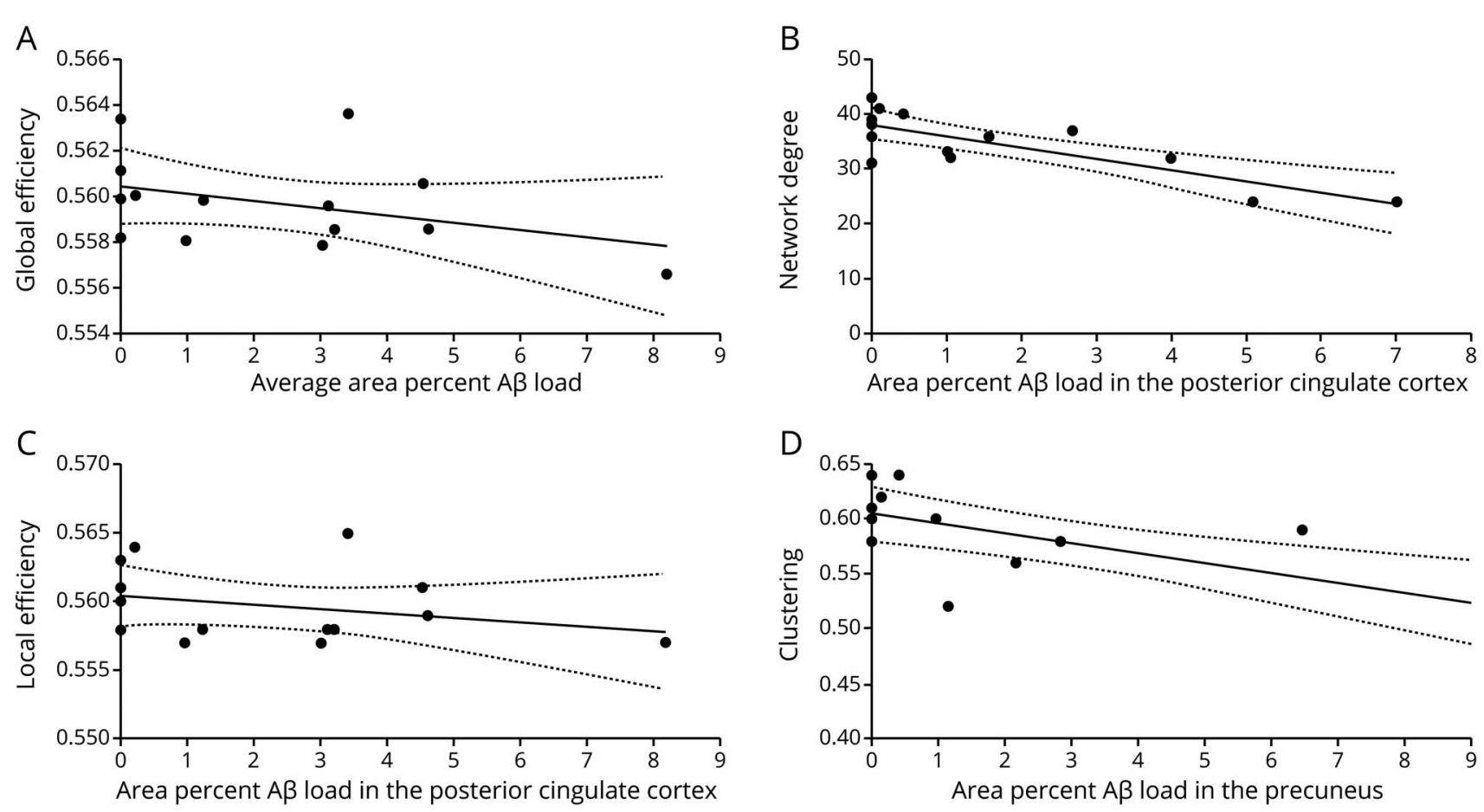

(A) Relationship between global efficiency and average $A \beta$ load of a subject, corrected for postmortem delay ( $R 2=0.15)$ (dotted line, $95 \%$ confidence interval $[C I])$. (B) $A$ higher percent $A \beta$ load is related to lower degree in the posterior cingulate cortex $\left(R^{2}=0.63\right)$ (dotted line, $95 \% \mathrm{Cl}$ ). (C) $A$ higher percent $A \beta$ load is related to a higher local efficiency in the posterior cingulate cortex $\left(R^{2}=0.41\right)$ (dotted line, $95 \% \mathrm{Cl}$ ). (D) $A$ higher percent $A \beta$ load is related to a lower clustering in the precuneus $\left(R^{2}=0.57\right.$ ) (dotted line, $95 \% \mathrm{Cl}$ ).

not change when controlling for presence of $\mathrm{p}$-tau. The network topology measures appear robust at thresholds ranging from $5 \%$ to $35 \%$ for degree and $20 \%-35 \%$ for local efficiency and clustering (table 2).

When exploring regional network topology within each of the 12 cortical regions for degree, local efficiency, and clustering, significant associations between regional area percent $A \beta$ load and degree were found in the posterior cingulate $(\beta=-2.22$ $[95 \% \mathrm{CI}-3.08,-1.35]$; FDR $p=0.002)$ and frontal pole $(\beta=$ 0.73 [95\% CI 0.01, 1.45]; FDR $p=0.08)$, the latter one not surviving FDR correction for multiple comparisons. This indicates that a higher percent $A \beta$ load is related to a lower degree of the posterior cingulate (figures $4 \mathrm{~B}$ and 5 ). In addition, a significant association between regional $A \beta$ load and local efficiency was found for the posterior cingulate $(\beta=1.01$ $\times 10^{-2}\left[95 \%\right.$ CI $\left.0.26 \times 10^{-2}, 1.76 \times 10^{-2}\right] ;$ FDR $p=0.02$ ) (figure $4 \mathrm{C}$ ), meaning more $\mathrm{A} \beta$ load is related to a higher local efficiency in the posterior cingulate. A significant association between regional $A \beta$ load and clustering was found for the precuneus $\left(\beta=-0.91 \times 10^{-2}\left[95 \% \mathrm{CI}-1.61 \times 10^{-2},-0.21 \times\right.\right.$ $\left.10^{-2}\right]$; FDR $\left.p=0.028\right)$ and posterior cingulate $(\beta=-3.03 \times$ $10^{-2}\left[95 \%\right.$ CI $\left.-6.22 \times 10^{-2}, 0.15 \times 10^{-2}\right]$; FDR $\left.p=0.1\right)$, the latter one not surviving FDR correction. This indicates that a higher percent $A \beta$ load is related to a lower clustering in the precuneus (figure 4D). These results seem robust for degree of the posterior cingulate at thresholds ranging from $10 \%$ to
$35 \%$ (table 3); for local efficiency and clustering, the results appear less robust at different thresholds.

When only taking into account sections that contained $A \beta$ load (i.e., excluding sections without pathology), association with global efficiency $(\mathrm{n}=10$ cases; $p=0.066)$ and network degree $(n=96$ tissue sections; $p=0.062)$ were no longer significant. A significant association between $A \beta$ load and clustering $\left(\beta=-0.62 \times 10^{-2}\left[95 \% \mathrm{CI}-1.22 \times 10^{-2},-0.01 \times\right.\right.$ $\left.\left.10^{-2}\right] ; p=0.045\right)$ and local efficiency $\left(\beta=3.54 \times 10^{-3}[95 \%\right.$ CI $\left.\left.0.31 \times 10^{-3}, 6.78 \times 10^{-3}\right] ; p=0.032\right)$ was still observed. Regionally, the association between $A \beta$ load and clustering and local efficiency was no longer significant (respectively $p=$ 0.143 and $p=0.054$ ), while the association between $\mathrm{A} \beta$ load and network degree remained significant $(\beta=-2.36[95 \% \mathrm{CI}$ $-3.68,-1.03]$; FDR $p=0.01)$.

\section{Relationship between p-tau load and network topology}

On a global, whole brain level $(n=14)$, no association between presence of $\mathrm{p}$-tau immunoreactivity and global efficiency was found. On a local level ( $\mathrm{n}=95$ sections across 8 regions), no significant association between the semiquantitative scoring of p-tau and degree or local efficiency was found. These results showed no change at different thresholds (5\%-45\%). When exploring regional network topology within each of the 8 cortical regions for degree, local efficiency, and clustering, only 
Table 2 Relationship between network topology measures and $\beta$-amyloid load at different network thresholds

\begin{tabular}{|c|c|c|c|c|c|}
\hline Threshold (in \%) & Statistics & Global efficiency & Degree & Local efficiency & Clustering \\
\hline \multirow[t]{4}{*}{5} & $\beta$ & $-4.98 \mathrm{E}-04$ & $-1.69 \mathrm{E}-01$ & $8.91 \mathrm{E}-03$ & $1.43 \mathrm{E}-02$ \\
\hline & Lower (95\% Cl) & $-2.58 \mathrm{E}-03$ & $-3.09 \mathrm{E}-01$ & $-8.64 \mathrm{E}-03$ & $-1.29 \mathrm{E}-03$ \\
\hline & Upper (95\% Cl) & $1.59 \mathrm{E}-03$ & $-2.98 \mathrm{E}-02$ & $2.65 \mathrm{E}-02$ & $2.99 \mathrm{E}-02$ \\
\hline & $p$ Value & 0.602 & $0.018^{a}$ & 0.317 & 0.072 \\
\hline \multirow[t]{4}{*}{10} & $\beta$ & $-4.98 \mathrm{E}-04$ & $-2.87 \mathrm{E}-01$ & $1.09 \mathrm{E}-03$ & $6.75 \mathrm{E}-03$ \\
\hline & Lower $(95 \% \mathrm{Cl})$ & $-2.58 \mathrm{E}-03$ & $-5.27 \mathrm{E}-01$ & $-5.19 \mathrm{E}-03$ & $-1.30 \mathrm{E}-04$ \\
\hline & Upper (95\% Cl) & $1.59 \mathrm{E}-03$ & $-4.65 \mathrm{E}-02$ & 7.37E-03 & $1.36 \mathrm{E}-02$ \\
\hline & $p$ Value & 0.602 & $0.020^{a}$ & 0.732 & 0.054 \\
\hline \multirow[t]{4}{*}{15} & $\beta$ & $-8.68 \mathrm{E}-04$ & $-3.54 \mathrm{E}-01$ & $2.64 \mathrm{E}-03$ & $4.62 \mathrm{E}-03$ \\
\hline & Lower (95\% Cl) & $-1.60 \mathrm{E}-03$ & $-6.97 \mathrm{E}-01$ & $-8.71 \mathrm{E}-04$ & $-1.59 \mathrm{E}-03$ \\
\hline & Upper (95\% Cl) & $-1.35 \mathrm{E}-04$ & $-1.07 \mathrm{E}-02$ & $6.16 \mathrm{E}-03$ & $1.08 \mathrm{E}-02$ \\
\hline & $p$ Value & $0.025^{\mathrm{a}}$ & $0.043^{a}$ & 0.139 & 0.143 \\
\hline \multirow[t]{4}{*}{20} & $\beta$ & $-8.30 \mathrm{E}-04$ & $-4.72 \mathrm{E}-01$ & $3.17 \mathrm{E}-03$ & $-5.55 \mathrm{E}-03$ \\
\hline & Lower (95\% Cl) & $-1.45 \mathrm{E}-03$ & $-9.09 \mathrm{E}-01$ & $2.19 \mathrm{E}-04$ & $-1.09 \mathrm{E}-02$ \\
\hline & Upper (95\% Cl) & $-2.13 E-04$ & $-3.50 \mathrm{E}-02$ & $6.11 \mathrm{E}-03$ & $-1.67 \mathrm{E}-04$ \\
\hline & $p$ Value & $0.014^{\mathrm{a}}$ & $0.034^{a}$ & $0.035^{a}$ & $0.043^{a}$ \\
\hline \multirow[t]{4}{*}{25} & $\beta$ & $-9.20 \mathrm{E}-04$ & $-5.38 \mathrm{E}-01$ & 4.17E-03 & $8.27 \mathrm{E}-03$ \\
\hline & Lower (95\% Cl) & $-1.83 \mathrm{E}-03$ & $-1.07 E+00$ & $1.21 \mathrm{E}-03$ & $2.48 \mathrm{E}-03$ \\
\hline & Upper $(95 \% \mathrm{Cl})$ & $-9.34 \mathrm{E}-06$ & $-8.84 \mathrm{E}-03$ & $7.12 \mathrm{E}-03$ & $1.41 \mathrm{E}-02$ \\
\hline & $p$ Value & $0.048^{a}$ & $0.046^{a}$ & $0.006^{b}$ & $0.005^{b}$ \\
\hline \multirow[t]{4}{*}{30} & $\beta$ & $-6.11 \mathrm{E}-04$ & $-6.68 \mathrm{E}-01$ & $3.50 \mathrm{E}-03$ & $6.93 \mathrm{E}-03$ \\
\hline & Lower (95\% Cl) & $-1.23 \mathrm{E}-03$ & $-1.29 \mathrm{E}+00$ & $4.45 \mathrm{E}-04$ & $8.81 \mathrm{E}-04$ \\
\hline & Upper $(95 \% \mathrm{Cl})$ & $1.17 \mathrm{E}-05$ & $-4.60 \mathrm{E}-02$ & $6.55 \mathrm{E}-03$ & $1.30 \mathrm{E}-02$ \\
\hline & $p$ Value & 0.054 & $0.035^{a}$ & $0.025^{a}$ & $0.025^{a}$ \\
\hline \multirow[t]{4}{*}{35} & $\beta$ & $-4.99 \mathrm{E}-04$ & $-7.53 \mathrm{E}-01$ & $3.25 \mathrm{E}-03$ & $6.47 \mathrm{E}-03$ \\
\hline & Lower (95\% CI) & $-1.07 E-03$ & $-1.46 \mathrm{E}+00$ & $2.25 \mathrm{E}-04$ & $4.22 \mathrm{E}-04$ \\
\hline & Upper $(95 \%$ Cl) & $6.96 \mathrm{E}-05$ & $-5.08 \mathrm{E}-02$ & $6.27 \mathrm{E}-03$ & $1.25 \mathrm{E}-02$ \\
\hline & $p$ Value & 0.078 & $0.036^{a}$ & $0.035^{\mathrm{a}}$ & $0.036^{a}$ \\
\hline \multirow[t]{4}{*}{40} & $\beta$ & $-2.32 \mathrm{E}-04$ & $-7.32 \mathrm{E}-01$ & $2.28 \mathrm{E}-03$ & 4.33E-03 \\
\hline & Lower (95\% Cl) & $-5.64 \mathrm{E}-04$ & $-1.50 E+00$ & $-5.28 \mathrm{E}-04$ & $-1.23 \mathrm{E}-03$ \\
\hline & Upper (95\% Cl) & $1.01 \mathrm{E}-04$ & $3.28 \mathrm{E}-02$ & $5.09 \mathrm{E}-03$ & $9.88 \mathrm{E}-03$ \\
\hline & $p$ Value & 0.150 & 0.061 & 0.111 & 0.126 \\
\hline \multirow[t]{4}{*}{45} & $\beta$ & $-2.36 \mathrm{E}-04$ & $-7.47 \mathrm{E}-01$ & $2.28 \mathrm{E}-03$ & $4.45 \mathrm{E}-03$ \\
\hline & Lower $(95 \% \mathrm{Cl})$ & $-5.78 \mathrm{E}-04$ & $-1.57 E+00$ & $-2.97 \mathrm{E}-04$ & $-6.98 \mathrm{E}-04$ \\
\hline & Upper (95\% Cl) & $1.06 \mathrm{E}-04$ & $7.55 \mathrm{E}-02$ & $4.86 \mathrm{E}-03$ & $9.59 \mathrm{E}-03$ \\
\hline & $p$ Value & 0.153 & 0.075 & 0.082 & 0.090 \\
\hline
\end{tabular}

Abbreviation: $\mathrm{Cl}=$ confidence interval.

${ }^{\text {a }} p<0.05$.

b $p<0.01$. 
Table 3 False discovery rate-corrected $p$ values for relationship between regional network topology measures and $\beta$-amyloid load at different network thresholds

\begin{tabular}{|c|c|c|c|c|c|c|c|c|c|}
\hline Location/threshold & 5 & 10 & 15 & 20 & 25 & 30 & 35 & 40 & 45 \\
\hline \multicolumn{10}{|l|}{ Degree $^{a}$} \\
\hline Posterior cingulate & - & 0.018 & 0.002 & 0.000 & 0.005 & 0.008 & 0.027 & - & - \\
\hline Frontal pole & - & - & 0.047 & - & 0.042 & - & - & - & - \\
\hline Enthorhinal cortex & - & - & 0.040 & - & 0.043 & - & - & - & - \\
\hline \multicolumn{10}{|l|}{ Local efficiency ${ }^{a}$} \\
\hline Posterior cingulate & - & 0.002 & 0.003 & 0.023 & - & 0.022 & 0.042 & - & - \\
\hline Inferior parietal lobe & - & - & - & - & 0.032 & - & - & - & - \\
\hline \multicolumn{10}{|l|}{ Clustering $^{a}$} \\
\hline Precuneus & - & - & - & 0.028 & - & - & - & - & - \\
\hline Posterior cingulate & - & 0.003 & 0.002 & - & - & 0.020 & 0.032 & - & - \\
\hline Inferior parietal lobe & - & - & - & - & 0.032 & - & - & - & - \\
\hline
\end{tabular}

a Only regions with significant false discovery rate-corrected $p$ values are shown.

a trend associations between $\mathrm{p}$-tau and clustering was found for the anterior cingulate cortex $(p=0.052$; not FDR corrected).

\section{Discussion}

In this study, we sought to investigate the association between $\mathrm{A} \beta$ and $\mathrm{p}$-tau load and structural network topology in non- neurologic brain donors with no or low $\mathrm{AD}$-related pathologic change. Using our combined postmortem in situ MRI and histopathology approach, an association was found between higher $\mathrm{A} \beta$ load, predominantly of diffuse type, and measures of lower integration (global efficiency), lower centrality (degree), and lower segregation (lower centrality and higher local efficiency) of brain network organization. Of the analyzed regions, this was particularly the case for the posterior

Figure 5 Two non-neurologic cases with differential pathologic burden and network topology

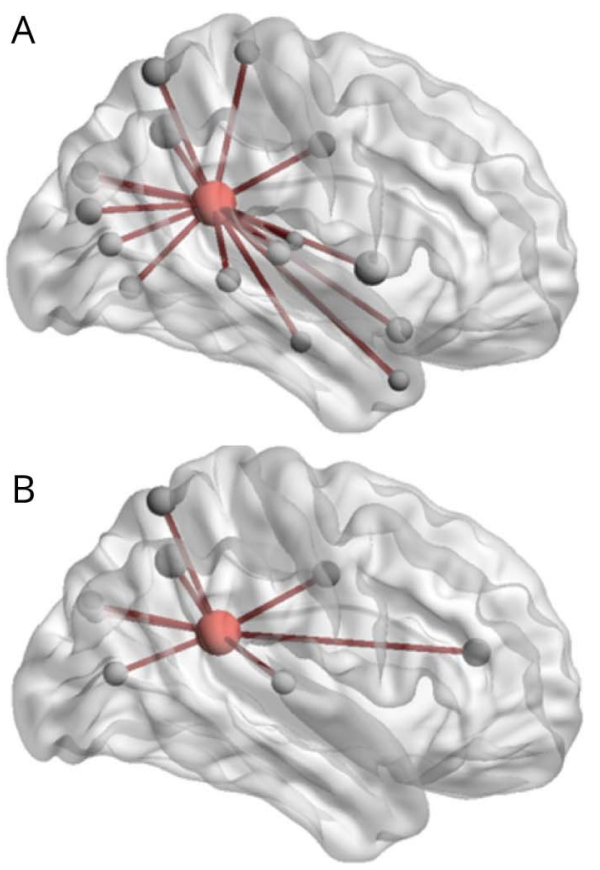

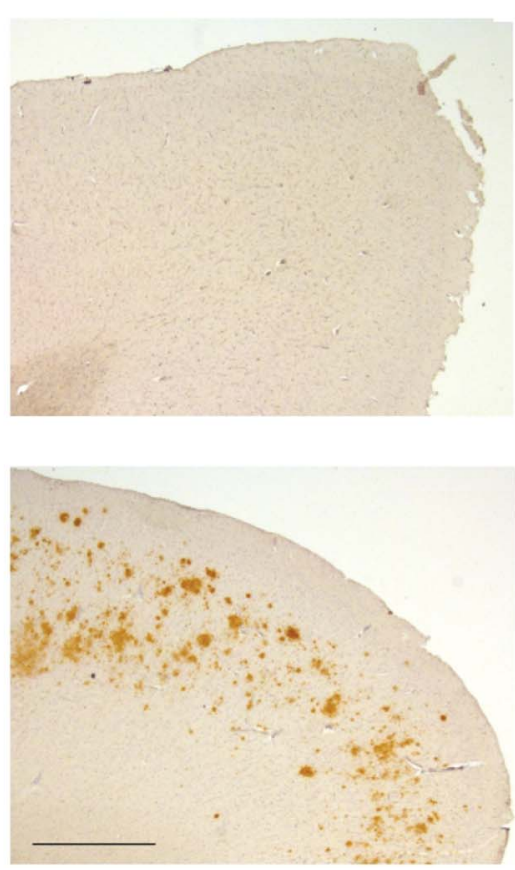

(A) A 77-year-old man without $\beta$-amyloid $(A \beta)$ pathologic burden in the posterior cingulate cortex (PCC) of the right hemisphere (case 9 from table 1). (B) A 68-year-old woman with $7 \% A B$ pathologic burden in the PCC (case 1 from table 1) of the right hemisphere. Presence of $A B$ load in the PCC is related to fewer connections between the PCC (in red) and cortical (gray) areas. Scale bar: $1 \mathrm{~mm}$. 
cingulate cortex and precuneus. Changes in network topology in these regions may be explored as an early biological marker for microstructural changes related to $A \beta$ pathology.

Staging of $\mathrm{A} \beta$ deposition throughout the brain has been described by Thal et al. ${ }^{31}$ through postmortem investigation of patients with and without dementia and $\mathrm{AD}$-related pathology. In our study of non-neurologic cases who did not meet the pathologic criteria for $\mathrm{AD}$, most cortical regions showed some extent of $A \beta$ pathology, of which the frontal and parietal regions were generally more abundantly involved, which is consistent with previous findings in the literature. ${ }^{1,6}$ In addition, $A \beta$ plaques are commonly classified into diffuse or classic plaques based on their morphology. ${ }^{27}$ Although both types (diffuse and classic) were seen in our cases, they were predominantly of diffuse type. The sequential development of plaques is up for debate: some researchers argue that diffuse plaques evolve over time into dense core plaques, ${ }^{34}$ while others propose that morphologically distinct plaques have different origins. ${ }^{35} \mathrm{Nev}$ ertheless, diffuse plaques are seen more frequently in the earliest stages of $A \beta$ plaque formation, as shown in our and other studies, ${ }^{27}$ and are more difficult to capture with in vivo PET. ${ }^{36}$

The preclinical phases of $\mathrm{AD}$ are generally associated with $\mathrm{A} \beta$ depositions in the absence of $\mathrm{p}$-tau pathology outside the medial temporal lobe. ${ }^{37,38}$ Due to the sparsity of $\mathrm{p}$-tau in our cohort, mainly some pretangles and aging-related tau astrogliopathy, no association with network topologic measures of integration, centrality, and segregation was found.

A major strength of the current study is the feasibility to create a structural network with subsequent network topology with postmortem in situ MRI data. In situ DTI tractography has shown to be feasible postmortem, ${ }^{39}$ and structural network topology has been derived from in situ MRI cases based on a group-based structural connectivity atlas in healthy patients in vivo. ${ }^{40}$ To our knowledge, this study is the first to derive network topology from single-subject in situ MRI cases. Relating network topology results from our study to the in vivo literature, overlap in the highly connected (or hub) regions was seen, such as the precuneus, posterior cingulate, and insular cortex. ${ }^{32,33}$ Future postmortem in situ MRI studies will need to assess whether other network topology measures (e.g., modularity) show similar consistencies in vivo and in situ.

Structural network alterations in the context of regional $A \beta$ accumulation have been explored in vivo. ${ }^{711,41-43}$ However, most of these studies assessed this relationship across different (e.g., diagnostic) groups, rendering it impossible to interpret a linear association within one specific group (e.g., early $A \beta$ accumulation). For instance, a study by Prescott and colleagues, ${ }^{12}$ who used A $\beta$ PET to identify regions with $A \beta$ load, found increased cortical $A \beta$ accumulation across diagnostic groups (normal cognition, mild cognitive impairment, and $\mathrm{AD}$ ) to be associated with a decrease in network degree and local efficiency. In turn, only one study looked at the association between single-subject network topology and continuous $A \beta$
CSF levels in cognitively normal adults. This study found an association between lower $A \beta$ CSF levels (suggesting $A \beta$ accumulation) and lower network degree and lower global effciency, ${ }^{41}$ which is in line with the results from our study, suggesting a link between incipient $A \beta$ pathology and reduced centrality and information integration.

Also in line with the study by Tijms et al. ${ }^{41}$ is the association between $A \beta$ load and a less segregated brain organization. Although there are many methodologic differences between our study and the Tijms et al. ${ }^{41}$ study, such as method of calculating connectivity (GM structure vs probabilistic tractography) and measure of $A \beta$ load (CSF vs immunohistopathology), they seem to pick up on the same biological process. Nevertheless, further studies are warranted to assess the association between local network clustering and effciency and $A \beta$ load and accumulation.

A study by Palmqvist and colleagues ${ }^{44}$ showed that earliest accumulation of $A \beta$ PET occurs within the precuneus and medial orbitofrontal and posterior cingulate cortex, and that $A \beta$ starts accumulating before overt metabolic or atrophy changes. In accordance, Voevodskaya and colleagues ${ }^{11}$ found changes in network topology to occur before any detectable atrophy in CSF A $\beta$-positive cognitively normal adults. From our study it can also tentatively be inferred that network topology in the posterior cingulate cortex and precuneus may be a more sensitive marker for early $A \beta$ accumulation than global, GM, or WM atrophy or hippocampal volume, since the latter measures showed no relationship with $A \beta$ load. As such, within the Amyloid, Tau and Neurodegeneration $[\mathrm{AT}(\mathrm{N})]$ research framework as proposed by NIA-AA, ${ }^{3}$ (global or regional) brain network organization changes may be considered as an addition to the $(\mathrm{N})$ group, although cutoff points would need to be explored.

The posterior cingulate cortex has been shown to be a pivotal region susceptible to normal and pathologic aging processes such as $A \beta$ depositions. ${ }^{45} A \beta$ is believed to disrupt glial support, ${ }^{46}$ synaptic function, ${ }^{47}$ axonal transport, ${ }^{48}$ and/or cell-cell signaling. ${ }^{49}$ Although a causal relationship between $A \beta$ accumulation and network topology cannot be inferred from our study, further research is necessary to elucidate the interplay of these mechanisms and the potential role for network topology as an early biological marker for microstructural changes related to $\mathrm{A} \beta$ pathology.

Clinical information on the included donors was very limited, and no assessment of cognitive status was available, which can be seen as a limitation of our study. A second limitation is the small number of cases, although a previous in vivo study showed feasibility of structural network topology with fewer subjects $(\mathrm{n}=5)^{50}$; the observed variation in results at different thresholds may be reflected by this limitation. Nevertheless, the topologic measure of degree shows to be relatively robust at different thresholds in our sample. Furthermore, graph theoretical measures such as nodal global and local efficiency may 
be influenced by a node's network degree. There has not been an optimal methodologic suggestion to account for this, ${ }^{51}$ and therefore it remains a subject of debate. Finally, although we corrected for possible confounders such as age, sex, and postmortem delay in our study, other factors (e.g., body temperature and other pathologic processes upon death) may influence MRI acquisition and structural network topology and need to be taken into consideration when translating results from the in situ to the in vivo setting. Future imaging studies should further investigate the association between $A \beta$ accumulation, in situ network topology, in vivo network topology, and cognitive outcome in healthy aging and $\mathrm{AD}$.

Clinicopathologic studies indicate that low levels of $\mathrm{AD}$ related pathologic change in cognitively unimpaired individuals are associated with subtle cognitive deficits, specifically within the attention and working memory domain. ${ }^{52}$ Our study adds to this concept by showing that low levels of $\mathrm{AD}$ related pathologic change are associated with (regionspecific) changes in brain network organization. Combined, this suggests an interplay between early $\mathrm{AD}$-related pathologic change, brain network organization, and cognition, which may aid identification of individuals at risk for developing $\mathrm{AD}$.

Understanding the histopathologic signature of structural network topology in decedents without dementia is instrumental for the interpretation of structural network alteration in the living elderly, and by extension in pathologic aging such as $\mathrm{AD}$. This study also highlights the potential importance of posterior cingulate cortex and precuneus network topology as an early marker of $A \beta$ pathologic change.

\section{Acknowledgment}

The authors thank the donors of the body donation program and the NABCA MRI and autopsy teams for their continuing efforts.

\section{Study funding}

L.E.J. receives funding from the Alzheimer Association (Research Fellowship AARF-18-566,459). F.B. is supported by the NIHR biomedical research centre at UCLH. L.D. has received funding from the Netherlands Organization for Scientific Research (NWO Veni 016.146.086) and Society in Science (Branco Weiss Fellowship). W.D.J.v.d.B. is financially supported by grants from Amsterdam Neuroscience, ZonMW Memorabel, ZonMW Technology Hotel, Stichting Parkinson Fonds, Alzheimer Netherlands-LECMA, and contract research for Roche Pharma, Lysosomal Therapeutics, and Crossbeta Sciences.

\section{Disclosure}

L. Jonkman, M. Steenwijk, N. Boesen, and A. Rozemuller report no disclosures relevant to the manuscript. F. Barkhof is a consultant for Biogen-Idec, Janssen Alzheimer Immunotherapy, Bayer-Schering, Merck-Serono, Roche, Novartis, Genzyme, and Sanofi-Aventis; has received sponsoring from European Commission-Horizon 2020, National Institute for
Health Research-University College London Hospitals Biomedical Research Centre, Scottish Multiple Sclerosis Register, TEVA, Novartis, and Toshiba; is supported by the University College London Hospitals NHS Foundation Trust Biomedical Research Center; and serves on the editorial boards of Radiology, Brain, Neuroradiology, Multiple Sclerosis Journal, and Neurology. J. Geurts is editor for Europe at Multiple Sclerosis Journal and has received research support from Biogen, Sanofi Genzyme, and Novartis Pharma. L. Douw reports no disclosures relevant to the manuscript. W. van de Berg has been a consultant for CHDR Leiden and Lysosomal Therapeutics. Go to Neurology.org/N for full disclosures.

\section{Publication history}

Received by Neurology June 1, 2019. Accepted in final form January 14, 2020.

Appendix Authors

\begin{tabular}{|c|c|c|}
\hline Name & Location & Contribution \\
\hline $\begin{array}{l}\text { Laura } \\
\text { Jonkman, } \\
\text { PhD }\end{array}$ & $\begin{array}{l}\text { Amsterdam } \\
\text { UMC, Vrije } \\
\text { Universiteit }\end{array}$ & $\begin{array}{l}\text { Conception and design of the study, } \\
\text { acquisition and analysis of the data, } \\
\text { writing of the manuscript, provided } \\
\text { study funding }\end{array}$ \\
\hline $\begin{array}{l}\text { Martijn } \\
\text { Steenwijk, } \\
\text { PhD }\end{array}$ & $\begin{array}{l}\text { Amsterdam } \\
\text { UMC, Vrije } \\
\text { Universiteit }\end{array}$ & $\begin{array}{l}\text { Acquisition and analysis of the data, } \\
\text { provided critical revisions to the } \\
\text { manuscript }\end{array}$ \\
\hline $\begin{array}{l}\text { Nicky } \\
\text { Boesen, MSc }\end{array}$ & $\begin{array}{l}\text { Amsterdam } \\
\text { UMC, Vrije } \\
\text { Universiteit }\end{array}$ & $\begin{array}{l}\text { Acquisition and analysis of the data, } \\
\text { revision of the manuscript }\end{array}$ \\
\hline $\begin{array}{l}\text { Annemieke } \\
\text { Rozemuller, } \\
\text { PhD }\end{array}$ & $\begin{array}{l}\text { Amsterdam } \\
\text { UMC, Vrije } \\
\text { Universiteit }\end{array}$ & $\begin{array}{l}\text { Acquisition and analysis of the data, } \\
\text { provided critical revisions to the } \\
\text { manuscript }\end{array}$ \\
\hline $\begin{array}{l}\text { Frederik } \\
\text { Barkhof, PhD }\end{array}$ & $\begin{array}{l}\text { Amsterdam } \\
\text { UMC, Vrije } \\
\text { Universiteit; } \\
\text { UCL, London }\end{array}$ & $\begin{array}{l}\text { Analysis of data, provided critical } \\
\text { revisions to the manuscript }\end{array}$ \\
\hline $\begin{array}{l}\text { Jeroen } \\
\text { Geurts, PhD }\end{array}$ & $\begin{array}{l}\text { Amsterdam } \\
\text { UMC, Vrije } \\
\text { Universiteit }\end{array}$ & $\begin{array}{l}\text { Design of the study, provided } \\
\text { critical revisions to the manuscript }\end{array}$ \\
\hline $\begin{array}{l}\text { Linda Douw, } \\
\text { PhD }\end{array}$ & $\begin{array}{l}\text { Amsterdam } \\
\text { UMC, Vrije } \\
\text { Universiteit }\end{array}$ & $\begin{array}{l}\text { Design of the study, provided } \\
\text { critical revisions to the manuscript }\end{array}$ \\
\hline $\begin{array}{l}\text { Wilma van de } \\
\text { Berg, PhD }\end{array}$ & $\begin{array}{l}\text { Amsterdam } \\
\text { UMC, Vrije } \\
\text { Universiteit }\end{array}$ & $\begin{array}{l}\text { Acquisition of the data, design of the } \\
\text { study, provided critical revisions to } \\
\text { the manuscript, provided study } \\
\text { funding }\end{array}$ \\
\hline
\end{tabular}

\section{References}

1. Price JL, Morris JC. Tangles and plaques in nondemented aging and "preclinical" Alzheimer's disease. Ann Neurol 1999;45:358-368.

2. Jagust W. Imaging the evolution and pathophysiology of Alzheimer disease. Nat Rev Neurosci 2018;19:687-700.

3. Jack CR, Bennett DA, Blennow K, et al. NIA-AA Research Framework: toward a biological definition of Alzheimer's disease. Alzheimer's Dement 2018;14:535-562.

4. Sperling R, Mormino E, Johnson K. The evolution of preclinical Alzheimer's disease: implications for prevention trials. Neuron 2014;84:608-622.

5. Jack CR, Knopman DS, Jagust WJ, et al. Tracking pathophysiological processes in Alzheimer's disease: an updated hypothetical model of dynamic biomarkers. Lancet Neurol 2013;12:207-216.

6. Braak H, Braak E. Neuropathological stageing of Alzheimer-related changes. Acta Neuropathol 1991;82:239-259. 
7. Pereira JB, Strandberg TO, Palmqvist S, et al. Amyloid network topology characterizes the progression of Alzheimer's disease during the predementia stages. Cereb Cortex 2018;28:340-349.

8. Gong G, Rosa-Neto P, Carbonell F, Chen ZJ, He Y, Evans AC. Age- and gender-related differences in the cortical anatomical network. J Neurosci 2009;29:15684-15693.

9. Yao Z, Zhang Y, Lin L, et al. Abnormal cortical networks in mild cognitive impairment and Alzheimer's disease. Plos Comput Biol 2010;6:e1001006.

10. Lo CY, Wang PN, Chou KH, Wang J, He Y, Lin CP. Diffusion tensor tractography reveals abnormal topological organization in structural cortical networks in Alzheimer's disease. J Neurosci 2010;30:16876-16885.

11. Voevodskaya O, Pereira JB, Volpe G, et al. Altered structural network organization in cognitively normal individuals with amyloid pathology. Neurobiol Aging 2018;64:15-24.

12. Prescott JW, Guidon A, Doraiswamy PM, Roy Choudhury K, Liu C, Petrella JR. The Alzheimer structural connectome: changes in cortical network topology with increased amyloid plaque burden. Radiology 2014;273:175-184.

13. Ikonomovic MD, Klunk WE, Abrahamson EE, et al. Post-mortem correlates of in vivo PiBPET amyloid imaging in a typical case of Alzheimer's disease. Brain 2008;131:1630-1645.

14. Thal DR, Attems J, Ewers M. Spreading of amyloid, tau, and microvascular pathology in Alzheimer's disease: findings from neuropathological and neuroimaging studies. J Alzheimers Dis 2014;42(suppl 4):S421-S429.

15. Jonkman LE, Graaf YG, Bulk M, et al. Normal Aging Brain Collection Amsterdam (NABCA): a comprehensive collection of postmortem high-field imaging, neuropathological and morphometric datasets of non-neurological controls. Neuroimage Clin 2019;22:101698.

16. Montine TJ, Phelps CH, Beach TG, et al. National Institute on Aging-Alzheimer's Association guidelines for the neuropathologic assessment of Alzheimer's disease: a practical approach. Acta Neuropathol 2012;123:1-11.

17. Hyman BT, Phelps CH, Beach TG, et al. National Institute on Aging-Alzheimer's Association guidelines for the neuropathologic assessment of Alzheimer's disease. Alzheimer's Dement. 2012;8:1-13.

18. Jenkinson M, Beckmann CF, Behrens TEJ, Woolrich MW, Smith SM. FSL. Neuroimage 2012;62:782-790.

19. Chard DT, Jackson JS, Miller DH, Wheeler-Kingshott CAM. Reducing the impact of white matter lesions on automated measures of brain gray and white matter volumes. J Magn Reson Imaging 2010;32:223-228.

20. Greve DN, Fischl B. Accurate and robust brain image alignment using boundarybased registration. Neuroimage NIH Public Access 2009;48:63-72.

21. Tzourio-Mazoyer N, Landeau B, Papathanassiou D, et al. Automated anatomical labeling of activations in SPM using a macroscopic anatomical parcellation of the MNI MRI single-subject brain. Neuroimage 2002;15:273-289.

22. Sotiropoulos SN, Zalesky A. Building connectomes using diffusion MRI: why, how and but. NMR Biomed 2019;32:e3752.

23. Achard S, Bullmore E. Efficiency and cost of economical brain functional networks. Plos Comput Biol Public Libr Sci 2007;3:e17.

24. Dice LR. Measures of the amount of ecologic association between species. Ecology 1945;26:297-302.

25. Rubinov M, Sporns O. Complex network measures of brain connectivity: uses and interpretations. Neuroimage Acad Press 2010;52:1059-1069.

26. Latora V, Marchiori M. Efficient behavior of small-world networks. Phys Rev Lett Am Phys Soc 2001;87:198701.

27. Thal DR, Rüb U, Schultz C, et al. Sequence of Abeta-protein deposition in the human medial temporal lobe. J Neuropathol Exp Neurol 2000;59:733-748.

28. Alafuzoff I, Arzberger T, Al-Sarraj S, et al. Staging of neurofibrillary pathology in Alzheimer's disease: a study of the BrainNet Europe Consortium. Brain Pathol 2008; 18:484-496.

29. Benjamini Y, Hochberg Y; Journal of the Royal Statistical Society. Controlling the false discovery rate: a practical and powerful approach to multiple testing. J Royal Stat Soc Series B 1995:57:289-300.
30. Scheltens P, Leys D, Barkhof F, et al. Atrophy of medial temporal lobes on MRI in "probable" Alzheimer's disease and normal ageing: diagnostic value and neuropsychological correlates. J Neurol Neurosurg Psychiatry 1992;55:967-972.

31. Thal DR, Rüb U, Orantes M, Braak H. Phases of A beta-deposition in the human brain and its relevance for the development of AD. Neurology 2002;58:1791-1800.

32. Perry A, Wen W, Lord A, et al. The organisation of the elderly connectome. Neuroimage 2015;114:414-426.

33. van den Heuvel MP, Sporns O. Rich-club organization of the human connectome. J Neurosci 2011;31:15775-15786.

34. Griffin WS, Sheng JG, Roberts GW, Mrak RE. Interleukin-1 expression in different plaque types in Alzheimer's disease: significance in plaque evolution. J Neuropathol Exp Neurol 1995;54:276-281.

35. D'Andrea M, Nagele R. Morphologically distinct types of amyloid plaques point the way to a better understanding of Alzheimer's disease pathogenesis. Biotech Histochem 2010;85:133-147.

36. Thal DR, Beach TG, Zanette M, et al. [18F] flutemetamol amyloid positron emission tomography in preclinical and symptomatic Alzheimer's disease: specific detection of advanced phases of amyloid- $\beta$ pathology. Alzheimers Dement 2015;11:975-985.

37. Braak H, Braak E, Bohl J, Reintjes R. Age, neurofibrillary changes, A beta-amyloid and the onset of Alzheimer's disease. Neurosci Lett 1996;210:87-90.

38. Dickson DW, Crystal HA, Mattiace LA, et al. Identification of normal and pathological aging in prospectively studied nondemented elderly humans. Neurobiol Aging 1992; 13:179-189.

39. Flach PM, Schroth S, Schweitzer W, et al. Deep into the fibers! Postmortem diffusion tensor imaging in forensic Radiology. Am J Forensic Med Pathol 2015;36:153-161.

40. Kiljan S, Meijer KA, Steenwijk MD, et al. Structural network topology relates to tissue properties in multiple sclerosis. J Neurol 2018.

41. Tijms BM, Kate MT, Wink AM, et al. Gray matter network disruptions and amyloid beta in cognitively normal adults. Neurobiol Aging 2016;37:154-160.

42. Prescott JW, Guidon A, Doraiswamy PM, et al. The Alzheimer structural connectome: changes in cortical network topology with increased amyloid plaque burden. Radiology 2014;273:175-184.

43. Sepulcre J, Sabuncu MR, Becker A, Sperling R, Johnson KA. In vivo characterization of the early states of the amyloid-beta network. Brain 2013;136:2239-2252.

44. Palmqvist S, Schöll M, Strandberg O, et al. Earliest accumulation of $\beta$-amyloid occurs within the default-mode network and concurrently affects brain connectivity. Nat Commun 2017;8:1214.

45. Buckner RL, Sepulcre J, Talukdar T, et al. Cortical hubs revealed by intrinsic functional connectivity: mapping, assessment of stability, and relation to Alzheimer's disease. J Neurosci 2009;29:1860-1873.

46. Chen J, Zhou Y, Mueller-Steiner S, et al. SIRT1 protects against microglia-dependent amyloid- $\beta$ toxicity through inhibiting NF- $\mathrm{kB}$ signaling. J Biol Chem 2005;280 40364-40374.

47. Palop JJ, Mucke L. Synaptic depression and aberrant excitatory network activity in Alzheimer's disease: two faces of the same coin? Neuromolecular Med 2010;12: $48-55$.

48. Wirths O, Weis J, Szczygielski J, Multhaup G, Bayer TA. Axonopathy in an APP/PS1 transgenic mouse model of Alzheimer's disease. Acta Neuropathol 2006;111: 312-319.

49. Garden GA, La Spada AR. Intercellular (Mis)communication in neurodegenerative disease. Neuron 2012;73:886-901.

50. Hagmann P, Cammoun L, Gigandet X, et al. Mapping the structural core of human cerebral cortex. PLoS Biol 2008;6:e159.

51. van Wijk BCM, Stam CJ, Daffertshofer A. Comparing brain networks of different size and connectivity density using graph theory. PLoS One 2010;5:e13701.

52. Bennett DA, Wilson RS, Boyle PA, Buchman AS, Schneider JA. Relation of neuropathology to cognition in persons without cognitive impairment. Ann Neurol 2012; 72:599-609. 


\section{Neurology}

\section{Relationship between $\beta$-amyloid and structural network topology in decedents without dementia}

Laura E. Jonkman, Martijn D. Steenwijk, Nicky Boesen, et al.

Neurology 2020;95;e532-e544 Published Online before print July 13, 2020

DOI 10.1212/WNL.0000000000009910

This information is current as of July 13, 2020

\section{Updated Information \&} Services

References

Citations

Subspecialty Collections

Permissions \& Licensing

Reprints including high resolution figures, can be found at: http://n.neurology.org/content/95/5/e532.full

This article cites 51 articles, 7 of which you can access for free at: http://n.neurology.org/content/95/5/e532.full\#ref-list-1

This article has been cited by 1 HighWire-hosted articles: http://n.neurology.org/content/95/5/e532.full\#\#otherarticles

This article, along with others on similar topics, appears in the following collection(s):

\section{Alzheimer's disease}

http://n.neurology.org/cgi/collection/alzheimers_disease

\section{Cognitive aging}

http://n.neurology.org/cgi/collection/cognitive_aging

MRI

http://n.neurology.org/cgi/collection/mri

Information about reproducing this article in parts (figures,tables) or in its entirety can be found online at:

http://www.neurology.org/about/about_the_journal\#permissions

Information about ordering reprints can be found online:

http://n.neurology.org/subscribers/advertise

Neurology ${ }^{\circledR}$ is the official journal of the American Academy of Neurology. Published continuously since 1951, it is now a weekly with 48 issues per year. Copyright Copyright ( 2020 The Author(s). Published by Wolters Kluwer Health, Inc. on behalf of the American Academy of Neurology.. All rights reserved. Print ISSN: 0028-3878. Online ISSN: 1526-632X.

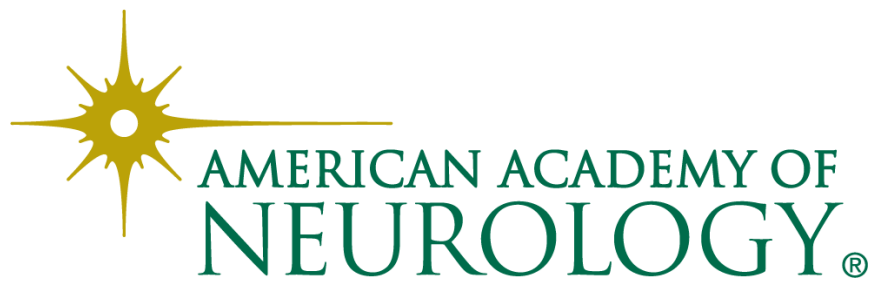

